\title{
Pengembangan Budidaya dan Pengolahan Kopi berbasis Agroforestry melalui Program KEHATi CSR PT. TIV Pandaan di Kawasan Gunung Arjuna Prigren Pasuruan
}

\author{
${\text { Fafit Rahmat Aji }{ }^{1} \text {; Mulyono Wibisono }}^{2}$; Rony Rusdiansyah $^{3}$; Diono Yusuf ${ }^{4}$ \\ ${ }^{1}$ Manager SR-CSR PT. TIV. Pandaan Kabupaten Pasuruan \\ ${ }^{2}$ SR/CSR spv PT. TIV. Pandaan Kabupaten Pasuruan \\ ${ }^{3}$ CorCom Manager PT. TIV. Pandaan Kabupaten Pasuruan \\ ${ }^{4}$ Ketua Yayasan Satu Daun Pasuruan \\ Email: mulyono.wibisono@danone.com
}

\begin{abstract}
ABSTRAK
Kajian ini merupakan hasil pendampingan masyarakat yang dilakukan oleh PT. Tirta Investama (PT. TIV) Pandaan Pasuruan melalui program corporate social responsibility, dengan dampingan Kelompok Tani Kopi Puspa Tani Makmur yang tersebar di Desa Jatiarjo, Dayurejo, Ledug, Pecalukan, Prigen dan Lumbangrejo di Kecamatan Prigen Kabupaten Pasuruan. Hasil kajian ini menunjukkan bahwa beberapa daerah di Kawasan Gunung Arjuna, tersebut memiliki tingkat keragaman dalam penanganan hayati. Belum semua desa memiliki dasar-dasar pengembangan agroforestry yang baik. Melalui program KEHATi dalam program CSR PT. TIV, komunitas petani yang tersebar di Kawasan Gunung Arjuna Prigen di dorong untuk mengembangkan kopi dan pengolahannya berbasis agroforestry dengan baik.
\end{abstract}

Kata Kunci: Budidaya Kopi; Agroforestry; Program KEHATi; PT. TIV Pandaan

\section{PENDAHULUAN}

Indonesia merupakan salah satu negara yang memiliki keanekaragaman hayati yang sangat tinggi. Hal ini bisa dilihat dari ekosistem, jenis dalam ekosistem, dan plasma nutfah (genetik) yang berada di dalam setiap jenisnya. Namun dalam perkembangannya, Indonesia juga salah satu negara yang memiliki keterancaman lingkungan yang tinggi, terutama terjadinya kepunahan jenis dan kerusakan habitat, yang menyebabkan menurunnya keanekaragaman hayati. Oleh karena itu, maka tidak heran apabila Indonesia menjadi salah satu wilayah prioritas konservasi keanekaragaman hayati di dunia (Suhartini 2009).

Dalam kajian Suhartini, berbagai problem terkait dengan masalah kerusakan habitat alam baik oleh aktivitas manusia, kesalahan kebijakan dan ketidakjelasan pengaturan dalam mengelola kawasan hutan dan laut maupun karena bencana alam. Beberapa kerusakan tersebut antara lain hilangnya 
hutan dataran rendah Sumatra karena penyusutannya lebih dari $2.5 \%$ per tahun, konversi hutan untuk kelapa sawit, pertanian, transmigrasi, pertambangan, perumahan dan adanya logging baik yang resmi maupun yang ilegal. Selain itu juga kerusakan pada sungai, danau dan pesisir termasuk di dalamnya kerusakan sumber perikanan. Sementara itu dalam pembangunan berkelanjutan diharapkan dapat memenuhi kebutuhan sekarang tanpa mengurangi kemampuan generasi yang akan datang (Suhartini 2009).

Maka dari itu, konservasi keanekaragaman hayati dengan memperhatikan peningkatan potensi produksi dengan pengelolaan yang ramah lingkungan hidup serta menjamin terciptanya kesempatan yang merata dan adil bagi semua orang (Suhartini 2009). Agar tujuan tersebut dapat tercipta, Margules mengungkapkan perlunya strategi konservasi dengan memilah daerah yang dialokasikan untuk produksi yang cocok untuk pengembangan perekonomian dan juga daerah yang khusus untuk perlindungan (Margules \& Pressey 2000).

Upaya ini juga sebagaimana dilakukan oleh PT. TIV Pandaan Paasuruan yang membuat kebijakan untuk pengembangan Perlindungan Keanekaragaman Hayati (kehati).
Kebijakan ini sebagai landasan Perusahaan untuk berkontribusi pada pelestarian lingkungan dan keanekaragaman hayati di kawasan Gunung Arjuno, Kecamatan Prigen dan Kabupaten Pasuruan. Komitmen tersebut diwujudkan melalui pengembangan Program Kehati Arjuno Lestari yang mencakup kegiatan konservasi flora dan fauna endemik lokal. Program ini melibatkan masyarakat setempat dalam proses perencanaan, perawatan dan monitoring program sejak tahun 2009. Wilayah program berada di Hutan Sapen Kelurahan Ledug Kecamatan Prigen Kabupaten Pasuruan, bekerja sama dengan Perum Perhutani Kelompok Pengelola Hutan (KPH) Pasuruan. Menurut hasil studi hidro- geologi oleh Universitas Merdeka Malang, area tersebut merupakan bagian dari SubDaerah Aliran Sungai (DAS) Kedung Larangan dan Rejoso, Kabupaten Pasuruan, Jawa Timur (Tim Penyusun 2015).

Kajian ini akan menguraikan upaya PT. TIV Pandaan melalui program corporate social responsibility dalam mengembangkan budidaya dan pengolahan pohon kopi terpadu bagi kelompok tani berbasis agroforestry melalui program KEHATi CSR PT. TIV 
Pandaan di Kawasan Gunung Arjuna Prigren Pasuruan.

\section{A. Rumusan Masalah}

Rumusan masalah dalam kajian ini adalah untuk mendeskripsikan budidaya dan pengolahan kopi berbasis agroforestry di Kawasan Gunung Arjuna Prigren Pasuruan.

\section{B. Metode Pendampingan}

Kajian ini merupakan hasil pendampingan masyarakat yang dilakukan oleh PT. TIV melalui program corporate social responsibility. Adapun komunitas dampingan adalah Kelompok Tani Kopi Puspa Tani Makmur yang tersebar di Desa Jatiarjo, Dayurejo, Ledug, Pecalukan, Prigen dan Lumbangrejo di Kecamatan Prigen Kabupaten Pasuruan. Adapun metode dampingan yang digunakan dengan menggunakan CBR (community based research). Metode ini sangat relevan digunakan untuk mengajak masyarakat untuk mengatasi permasalahan yang dialami oleh mereka, dan dicari solusinya oleh mereka secara bersama-sama, dengan kolaborasi antara peneliti dengan masyarakat. Dalam kontek ini, komunitas merupakan aspek terpenting sebagai elemen yang akan membaca dan menyelesaikan persoalan di masyarakat
(Tim Penyusun CBR UIN Sunan Ampel Surabaya, 2015:10-13). Adapun tahapan dalam CBR ini adalah (1) peletakan dasar (laying the foundation), (2) perencanaan penelitian (research planning), pengumpulan dan analisis data (information gathering and analysis), (4) aksi atas temuan (acting on findings) (Tim Penyusun CBR UIN Sunan Ampel Surabaya, 2015:56-70).

\section{Kajian Referensi Konservasi Hayati dan Agroforestry}

\section{Konservasi Hayati}

Hutan adalah sumberdaya alam yang harus dimanfaatkan secara arif untuk kesejahteraan rakyat. Telah banyak terjadi dampak negatif pengelolaan hutan yang tidak ramah lingkungan termasuk banjir, longsor dan kekeringan.

Dalam berbagai tempat, pengelolaan hutan sangat beragam. Ada yang cenderung mengeskploitasi, namun tidak sedikit yang tetap menjaga dengan kearifan lokal.

Hasil kajian dari Senoaji pada masyarakat Baduy sangat positif dalam pengelolaan hutan. Mereka dengan menerapkan autran-aturan dan norma-noma tradisional dalam perhubungan sosial dan dalam memanfaatkan sumberdaya hutan. Sistim sosial masyarakat Baduy dapat mengontrol eksploitasi hutan yang tidak ramah lingkungan. Pada saat yang sama 
masyarakat Baduy mempunyai tingkat pendapatan di atas garis kemiskinan (Senoaji, 2004).

Mencari format dalam pengelolaan hutan terkadang juga dimulai dari problem semakin menyusutnya luas hutan di sekitar mereka. Kajian dari Bruno Verbist dan kawan-kawan, mengungkapkan bahwa masih maraknya penebangan hutan liar yang terjadi di wilayah kecamatan: Kecamatan Way Tenong dan Kecamatan Sumberjaya, Kabupaten Lampung. Salah satu upaya yang sudah dilakukan adalah mengembangkan rehabilitasi hutan dengan mengembangkan para pembudidaya budidaya kopi yang semula berbentuk sistem monokultur, secara bertahap berubah menjadi budidaya kopi campuran dengan pohon-pohon penaung. Pengamatan menunjukkan bahwa sejalan dengan berlangsungnya penebangan hutan, terjadi pula penanaman kembali pohon-pohonan, sehingga degradasi hutan yang lebih parah dapat dicegah (Bruno Verbist et al. 2004).

\section{Agroforestry;}

Pemanasan global merupakan gejala dari adanya pengelolaan sumber daya alam (SDA) yang tidak berkelanjutan. Pemanasan global juga menyebabkan munculnya kekhawatiran dunia, karena dampaknya terhadap kehidupan dan kondisi bentang lahan dari semua Negara baik bagi negara penghasil (emisi) gas rumah kaca (GRK) maupun bukan. Indonesia merupakan salah satu negara emitor GRK terutama berasal dari pembakaran hutan dan pengeringan gambut, sehingga Indonesia menjadi salah satu bagian dari solusi pengurangan pemanasan global.

Secara umum tapak ekologi (ecological footprint) dunia telah melebihi ruang yang tersedia, maka penggunaan ruang harus seefisien mungkin. Penggunaan ruang harus multifungsional yang dapat menghasilkan kebutuhan pokok dan sekaligus memberikan layanan lingkungan yang dibutuhkan masyarakat dan kehidupan lainnya. Agroforestry merupakan tawaran yang dapat memberikan solusi multifungsional (van Noordwijk 2008).

Banyak kajian yang juga menguatkan bahwa sistem agroforestry diyakini memberikan sejumlah layanan ekosistem; bukti masa lalu dan sekarang jelas menunjukkan bahwa agroforestry, bisa menjadi pilihan yang layak dalam penggunaan lahan yang bermanfaat untuk mengurangi kemiskinan, menawarkan sejumlah layanan ekosistem dan manfaat lingkungan (Jose 2009).

Perlindungan dan penanaman pohon dalam sistem agroforestry dapat 
berfungsi sebagai langkah penting. Dalam hal ini bisa melihat implementasi agroforestry di Kepulauan Pasifik. Praktek agroforestry tradisional pernah membuat Kepulauan Pasifik menjadi bangsa yang paling mandiri dan bergizi baik di dunia. Dalam Kepulauan Pasifik, agroforestry yang paling efektif dilakukan dengan memanfaatkan spesies local yang ada disana untuk dikembangkan (Educators et al. 2000). Hasil kajian dari Alain Atangana, dkk., Agroforestry juga diakui sebagai pilihan terbaik dalam manajemen penggunaan lahan berkelanjutan di daerah tropis, karena menyediakan ekosistem ramah lingkungan sekaligus juga menyediakan kebutuhan sehari-hari bagi pengelola agroforestry (Atangana et al. 2014).

Dalam perkembangan di dunia, pasca Protokol Kyoto, agroforestry telah mendapatkan perhatian lebih sebagai salah satu strategi untuk menyerap karbon (C) dan mitigasi perubahan iklim global. Agroforestry juga telah diakui memiliki potensi terbesar untuk penyerapan karbon (Jose \& Bardhan 2012).

Sistem aplikasi agroforestry di India menunjukkan bahwa agroforestry yang dikembangkan berpotensi multifungsi dalam mendukung peningkatan mata pencaharian melalui produksi simultan makanan, pakan ternak dan kayu bakar serta mitigasi dampak perubahan iklim. Dengan demikian, sistem agroforestry di India memiliki kontribusi berbagai fungsi ekologi, sosial dan ekonomi (Pandey 2007). Secara detil, Pandey menulis kontribusi sistem agroforestry di India adalah sebagai berikut:

(i) biodiversity conservation; (ii) yield of goods and services to society; (iii) augmentation of the carbon storage in agroecosystems; (iv) enhancing the fertility of the soils, and (v) providing social and economic well-being to people (Pandey 2007).

Walaupun agroforestry menjadi pilihan yang baik, namun dalam perkembangan kebijakan masih sebagai aktivitas pertanian yang purifier, dan tidak sedikit para petani dan pengguna lahan lainnya tidak mengetahui ragam dan sisi kemanfaatan dari agroforestry ini (Buttoud et al. 2013).

\section{Pembahasan}

\section{Kondisi Umum Wilayah Dampingan}

Di Kawasan hutan Gunung Arjuna Pasuruan, secara administratif membentang di sejumlah desa diantaranya, Desa Jatiarjo, Dayurejo, Ledug, Pecalukan, Prigen dan Lumbangrejo di Kecamatan Prigen. Kawasan ini di kelola oleh UPT Tahura 
R. Soerjo, Perum Perhutani dan BKSDA Jawa Timur.

Sebagai kawasan konservasi, jenis hutan di kawasan Tahura R. Soerjo adalah hutan alam dan sebagian hutan tanaman. Di kawasan ini selayaknya banyak terdapat lahan terbuka dengan dominasi tanaman ilalang. Namun, saat ini hanya beberapa wilayah yang kondisi lahannya masih utuh. Hal itu diakibatkan peristiwa kebakaran yang selalu terjadi setiap tahunnya disebabkan beberapa aktifitas oknum masyarakat, seperti pembukaan lahan untuk pertanian dengan cara membakar, pembuatan perapian oleh wisatawan pendaki dan adanya unsur kesengajaan.

Di kawasan Tahura ini juga masih marak terjadi kegiatan penebangan pohon diantaranya untuk bahan baku arang kayu (charcoal) untuk pemenuhan ekonomi masyarakat desa penyangga terutama bagi masyarakat Desa Jatiarjo, Dayurejo dan Lumbangrejo.

Upaya pelaksanaan penanaman kembali yang belum maksimal, memperparah kondisi di kawasan ini. Sementara, potensi Tahura R. Soerjo kian menjadi daya tarik bagi para pendaki gunung dan pecinta alam lainnya.

Dalam pengelolaannya UPT Tahura, Kawasan Tahura yang memiliki ketinggian mulai dari 1000 sampai dengan 3.339 mdpl ini mengakomodir kelompok masyarakat yang tergabung dalam Kelompok Tani Tahura (KTT) sebagai tenaga penanam disetiap kegiatan reboisasi.

Di bawah ketinggian $1.000 \mathrm{mdpl}$ kawasan hutan dikelola oleh Perum Perhutani. Di kawasan ini terdapat daerah hutan lindung dan hutan produksi. Hutan produksi di tumbuhi tanaman jenis Mahoni (magahoni) dan Pinus (caribia) yang kondisinya masih lebih baik dibandingkan dengan kawasan hutan konservasi (Tahura R. Soerjo). Pasalnya, dalam pengelolaannya pihak Perhutani melibatkan masyarakat desa yang tergabung dalam Lembaga Masyarakat Desa Hutan (LMDH) sebagai mitranya. Masyarakat di kawasan ini memanfaatkan lahan bawah tegakan hutan Perhutani dengan tanaman pertanian (jagung, kacang, cabai dan lain-lain) dan tanaman perkebunan (kopi, cegkeh, coklat, pisang dan lain-lain). Namun demikian, di beberapa titik lokasi masih terdapat lahan terbuka dengan tanpa tegakan, terutama di daerah Dayurejo, Ledug dan Lumbangrejo.

Sementara itu, kawasan BKSDA sebagai daerah cagar alam di wilayah Tretes memiliki luas mencapai $12 \mathrm{Ha}$, pengelolaannya difokuskan pada pengembangan jasa wisata sedangkan 
hutan rakyat sebagai kawasan penyangga hutan Gunung Arjuna sebagian besar dimanfaatkan dengan tanaman campuran.

Model agroforestry lebih banyak mendominasi daerah di kawasan tersebut dengan peruntukan untuk memenuhi kebutuhan harian, bulanan bahkan kebutuhan jangka panjang masyarakat sekitar. Sehingga, keragaman tanaman dalam hutan rakyat lebih variatif, sesuai dengan kebutuhan keseharian masyarakat, mulai dari empon-empon, tanaman perkebunan dan tanaman kayu buah sampai dengan tanaman kayu produksi.

Untuk tanaman kayu yang biasanya digunakan untuk pemenuhan kebutuhan jangka panjang, masyarakat melakukan kegiatan penebangan di kawasan hutan rakyat tidak secara bersamaan. Mereka melakukannya dengan cara tebang pilih, sesuai dengan tingkat kebutuhannya. Di daerah ini, sebagian dari lahan ini dimanfaatkan untuk kegiatan pertanian semusim dengan sistem tadah hujan. Pertanian model ini banyak dilakukan di daerah Jatiarjo, Dayurejo, Ledug dan sebagian Desa Bulukandang, Ketanireng dan Lumbangrejo. Sementara desa di bawahnya, pemanfaatan lahannya untuk pertanian intensif, di tanah sawah (Tim Penyusun 2014).

\section{Pemetaan Wilayah}

Pemetaan wilayah yang dilakukan dalam program dampingan ini adalah di Kawasan Gunung Arjuna dengan desa dan kelurahan sebagai berikut: Desa Jatiarjo, Desa Dayurejo, Kelurahan Ledug, Kelurahan Pecalukan dan Kelurahan Prigen.

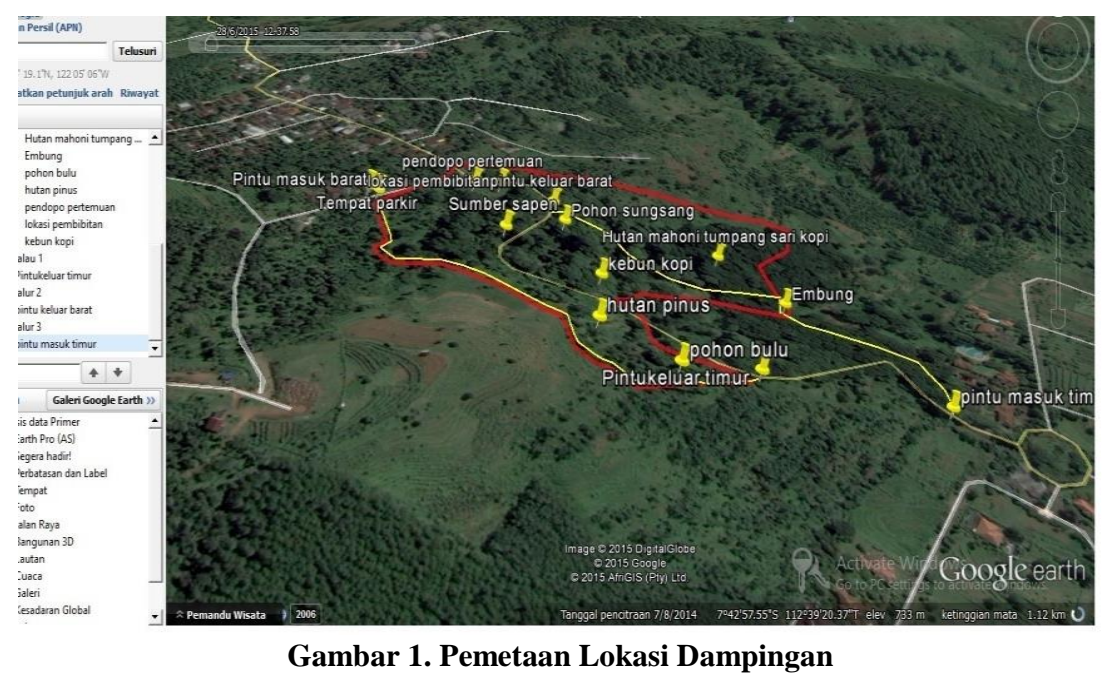




\section{a. Desa Jatiarjo}

Di desan Jatiarjo, kondisi vegetasi di kawasan Tahura dari sisi kerapatannya sangat memprihatinkan. Dalam setiap bulan tidak kurang dari 15 batang pohon di tebang secara liar. Pohon yang sudah berusia ratusan tahun tersebut dimanfaatkan oleh pelaku untuk bahan baku arang kayu (corchoal). Kegiatan ini masih terus berlangsung hingga kini yang tersebar di wilayah administrasi Desa Jatiarjo.

Secara keseluruhan, kawasan hutan lindung dan produksi pemanfaatannya banyak diarahkan dengan tanaman MPTS (tanaman yang dimanfaatkan hasil buah dan ikutan lainnya). Diantaranya, budidaya tanaman kopi, buah Alpukat, Nangka, Sirsat dan buah-buah lainnya. Kerapatan tanaman di kawasan ini, kondisinya lebih baik jika dibandingkan dengan kawasan konservasi. Namun beberapa kawasan yang tidak dilakukan pengelolaan oleh masyarakat, kondisinya kritis dan hanya ditumbuhi rumput dan perdu.

Hutan rakyat yang berada di wilayah administrasi Desa Jatiarjo sebagian besar sudah dikuasai oleh investor yang kebanyakan belum diketahui perencanaan penggunaannnya. Hal itu berdampak pada kualitas tutupan lahan yang berada di desa Jatiarjo. Sementara pada kawasan yang masih dimiliki oleh masyarakat banyak dikembangkan tanaman sengon dan tanaman kopi berbasis agroforestry. Pola tanam agroforestry dengan pemanfaatan lahan secara optimal, memperkaya jenis tanaman yang dimanfaatkan hasil buahnya. Sedangkan untuk tanaman kayu-kayuan masih dilakukan pengelolaan menggunakan sistem tebang butuh.

\section{b. Desa Dayurejo}

Desa Dayurejo memiliki wilayah administratif yang hampir sama dengan Desa Jatiarjo. Bentang alamnya mulai dari hutan rakyat, hutan produksi dan lindung yang di kelola oleh Perhutani dan kawasan konservasi di kawasan Taman Hutan Raya (TAHURA) R. Soerjo.

Vegetasi yang ada di kawasan ini didominasi dengan tanaman cemara gunung serta berbagai jenis bambu. Namun, terdapat pula punggunganpunggungan pegunungan yang justru kritis tanpa tanaman dan hanya ditumbuhi rumput seperti di kawasan Gunung Ringgit yang masih menjadi kesatuan dari pegunungan Arjuna. Di dalam area ini terdapat pula beberapa situs purbakala yang masih aktif digunakan oleh masyarakat sebagai sarana pemujaan dan kegiatan ritual religi yang lain. Situs yang disebut Indrokilo ini terdiri dari beberapa peninggalan sejarah yang tersebar di 
kawasan TAHURA yang masuk wilayah Desa Dayurejo.

Saat ini, tidak banyak Interaksi masyarakat kedalam kawasan ini selain melakukan kunjungan ke situs Indrokilo karena kondisi areanya tidak bisa dimanfaatkan untuk kebutuhan ekonomi. Kendati demikian, di kawasan ini terdapat sumber mata air "Putuk Bunder" yang dimanfaatkan oleh masyarakat Desa Dayurejo.

Kawasan hutan produksi dan lindung Perhutani yang ada di Jatiarjo dikembangkan oleh masyarakat yang tergabung tergabung dalam Lembaga Masyarakat Desa Hutan (LMDH) untuk menghasilkan buah, seperti tanaman kopi, alpukat, nangka, durian dan beberapa jenis lainnya. Bahkan, komoditi kopi menjadi tanaman pionir bagi masyarakat. Sementara kelas tanam Perhutani adalah pinus dan mahoni.

Saat ini, hutan rakyat yang ada di Desa Dayurejo juga sudah banyak dikembangkan untuk investasi para investor dari luar daerah. Sebagian sudah banyak beralih menjadi kawasan wisata dan sisanya masih dikelola oleh masyarakat untuk dimanfaatkan sebagai lahan pertanian dengan tanaman semusim dan budidaya tanaman sengon serta tanaman perkebunan seperti cengkeh dan kopi. Sementara yang dikembangkan dengan model agroforestry sudah sangat berkurang.

\section{c. Kelurahan Ledug}

Di kelurahan Ledug secara umum kondisi kawasan hutan konservasi dan hutan produksi serta hutan lindung masih terjaga dengan baik. Mulai dari kawasan konservasi, kawasan hutan produksi dan lindung. Sedangkan kawasan hutan rakyat sudah banyak beralih fungsi menjadi pemukiman dan sebagian masih tersisa sebagai lahan pertanian bunga dan perkebunan cengkeh. Di Ledug, terdapat sumber mata air "Tiban" yang berada di lahan hutan rakyat yang tersisa namun tanpa pengelolaan masyarakat karena lahannya milik desa. Sumber air ini mengaliri pertanian sawah dibawahnya. Menariknya, terdapat air terjun yang secara ekonomis belum termanfaatkan apalagi untuk kegiatan wisata.

Di kawasan hutan produksi dan lindung Perhutani mulai terjadi pengelolaan oleh masyarakat yang tergabung di LMDH Kelurahan Ledug. Mereka melakukan budidaya tanaman kopi dan cengkeh yang di tanam di sela-sela tanaman pinus dan mahoni milik Perhutani. Kegiatan ini berjalan paling akhir bila dibandingkan dengan kegiatan masyarakat di Desa Jatiajo dan Dayurejo. Kegiatan masyarakat ini menambah kerapatan tutupan lahan hutan yang ada. 
Kawasan hutan konservasi yang berbatasan dengan hutan produksi saat ini mulai dilakukan pemanfaatannya oleh masyarakat. Kegiatan yang dilaksanakan yakni melakukan budidaya tanaman cengkeh secara sepihak tanpa terkoordinasi dengan instansi TAHURA. Namun, antusias masyarakat dalam melakukan kegiatan ini terus berkembang.

\section{d. Kelurahan Pecalukan}

Interaksi masyarakat kelurahan Pecalukan tidak memberikan dampak yang signifikan terhadap kualitas sumberdaya hutan yang ada baik terhadap kawasan hutan produksi, hutan lindung maupun hutan konservasi. Perekonomian masyarakat yang berkembang baik menyebabkan hal itu tidak bisa dilakukan sehingga kegiatan pemanfaatan sumberdaya hutan untuk kegiatan perekonomian sangat kecil.

Di sisi lain, Kelurahan Pecalukan menjadi salah satu pintu pendakian bagi wisatawan yang akan mengadakan pendakian ke gunung Arjuna. Kegiatan pendakian ini memberi dampak terutama terjadinya kebakaran karena faktor kelalaian pendaki. Salah satu sumber mata air di kawasan konservasi adalah "Alap-alap". Sumber air ini dimanfaatkan oleh sebagian masyarakat Dayurejo, Ledug, Pecalukan serta Prigen.
Hutan produksi dan lindung Perhutani sebagian dikelola dengan tujuan wisata,sementara yang dikelola oleh untuk kegiatan pertanaian ditanami tanaman perkebunan yaitu kopi, salak, pisang dan tanaman buah lainnya.

Kelompok masyarakat yang tergabung dalam LMDH dengan jumlah anggota 40 orang tidak banyak yang melakukan pengelolaan lahan secara intensif. Namun, selain LMDH terdapat pula kelompok pelestari sumber air bernama paguyuban "Grojogan Sewu" yang aktif melakukan kegiatan pelestarian sumber mata air di kawasan hutan konservasi.

Kawasan hutan rakyat di Kelurahan Pecalukan tidak banyak karena lahannya sudah menjadi pemukiman. Akan tetapi masih terdapat sumber mata air yang dimanfaatkan oleh masyarakat yaitu sumber mata air "sumur watu" yang berada di tengah-tengah desa. Sumber air ini di kelola oleh RW 7 dan dimanfaatkan oleh sebanyak 40 Kepala Keluarga melalui koordinasi kelompok Himpunan Pengelola dan Pengguna Air (HIPPA) Kelurahan Pecalukan. Sayang, belum ada bentuk kegiatan yang dilaksanakan dalam upaya pelestarian sumber mata air oleh kelompok HIPPA.

Di wilayah administrasi Kelurahan Pecalukan terdapat kawasan suaka alam seluas $12 \mathrm{Ha}$ yang terletak di Tretes. 
Kawasan ini dialihfungsikan dan di bangun hotel namun mendapatkan penolakan dari masyarakat.

\section{Pendataan dan Pemeliharaan}

\section{Tanaman Kopi}

\section{a. Pendataan Petani Kopi}

Pendataan penggarap petani kopi di Desa Jatiarjo, Desa Dayurejo dan Kelurahan Ledug, Kelurahan Pecalukan penaman mulai tahun 2009 sampai dengan 2014 yang berada di Wilayah LMDH maupun Tahura R, Suryo Kabupaten Pasuruan, dilakukan pendataan di mulai Tanggal, 11 Mei 2015 s/d 23 Mei 2015 dengan cara melakukan kordinasi dengan beberapa pihak antara lain : LMDH Bumi lestari mulyo rejo Kelurahan Ledug,
LMDH Molyo Rejo Kel. Ledug, Pegawai Perhutani Pendamping LMDH, Ketua KTT Kelurahan Ledug, LMDH Jatiarjo, Kelompok Petani Kopi Puspa Tani Lingkungan Geneng Kel. Ledug, Ketua KTT Pecalukan, Petani Kopi Pecalukan, Kelompok Tani Sidodadi Lingkungan Paras Kel. Ledug, Petani Kopi Jatiarjo, dan Petani Kopi Desa Dayurejo.

Setelah pertemuan tersebut, dilakukan pengecekan dilapangan petani Kopi. Adapun hasil pendataan Desa Jatiarjo ,Desa Dayurejo dan Kelurahan Ledug serta Kelurahan Pecalukan Jumlah Petani Kopi dan Jumlah kopi adalah sebagai berikut:

Tabel 1. Penanaman Kopi Anggota Kelompok Tani Desa Jatiarjo, Desa Dayurejo Dan Kel. Ledug, Kel. Pecalukan Kecamatan Prigen

\begin{tabular}{|l|l|c|r|r|r|r|}
\hline No & Desa/Kel. & $\begin{array}{c}\text { Jumlah } \\
\text { Petani } \\
\text { Kopi }\end{array}$ & $\begin{array}{c}\text { Pohon } \\
\text { belum } \\
\text { berbuah }\end{array}$ & $\begin{array}{c}\text { Pohon } \\
\text { sudah } \\
\text { berbuah }\end{array}$ & Hasil/thn & $\begin{array}{c}\text { Jumlah } \\
\text { pohon }\end{array}$ \\
\hline 1 & Jatiarjo & 88 & 57745 & 26405 & 8,204 Ton & $\mathbf{8 4 1 5 0}$ \\
\hline 2 & Dayurejo & 6 & 5000 & 1410 & 0,537 Ton & $\mathbf{6 4 1 0}$ \\
\hline 3 & Ledug & 208 & 151626 & 18792 & 25,15 Ton & $\mathbf{1 7 0 4 1 8}$ \\
\hline 4 & Pecalukan & 61 & 10534 & 11484 & 12,548 Ton & $\mathbf{2 2 0 1 8}$ \\
\hline \multicolumn{2}{|r|}{ J u m l a h } & $\mathbf{2 2 4 9 0 5}$ & $\mathbf{5 8 0 9 1}$ & $\mathbf{4 6 , 4 3 9}$ ton & $\mathbf{2 8 2 9 9 6}$ \\
\hline
\end{tabular}

Dari hasil pendataan di atas di ambil kesimpulan bahwasannya penanaman kopi ada sebagian masyarakat yang telah melakukan penanaman dengan cara yang benar dan tepat di karenakan mereka ikut serta dalam pembinaan cara pembibitan dan penanaman maupun penyambungan
Kopi ataupun cara merawat sampai memanen agar mndapatkan hasil yang maksimal. Dan ada pula sebagian masyarakat yang melakukan penanaman kopi dengan cara yang lama yang penting hasil sehingga mereka tidak banyak mendapat hasil yang maksimal. 

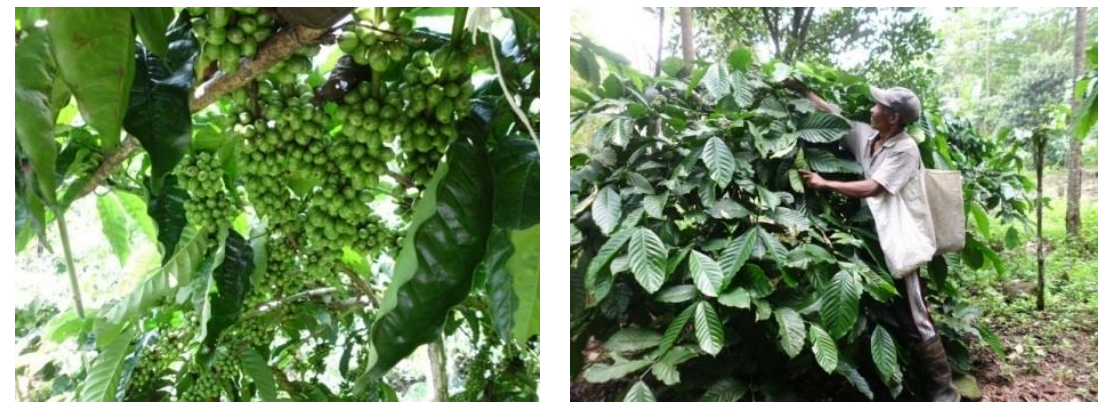

Gambar 2. Kondisi Buah Kopi di Lereng Gunung Arjuno

Penanaman kopi di Kelurahan Ledug, Kelurahan Pecalukan dan sebagian Kecil di Desa Jatiarjo Maupun Desa Dayurejo di lakukan pada tahun 2009 dari hasil surve di lapangan ada tanaman yang sudah pohonnya besar dan sebagian besar di lakukan penyambungan agar mendapatkan hasil yang maksimal, Contoh gambar bawah :
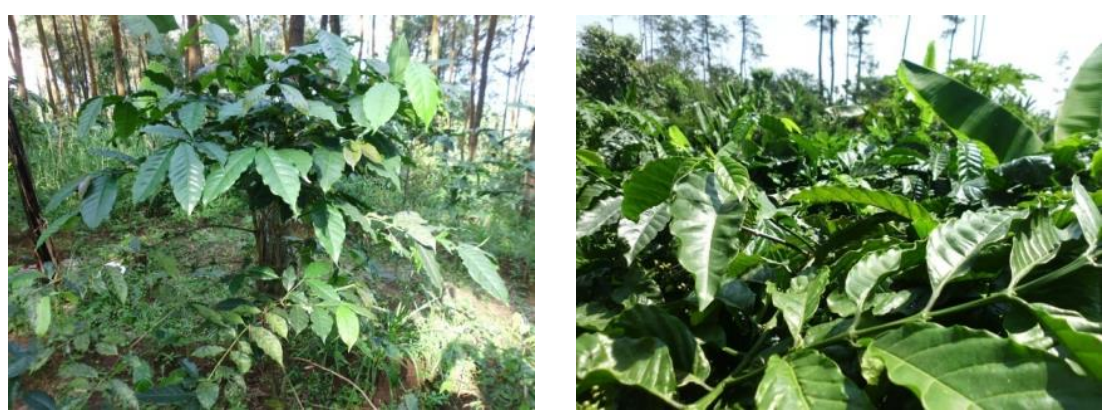

Gambar 3. Pohon Kopi yang baru berbuah

Ada juga yang baru di tanam yang mana penanamannya baru dilaukan pada tahun 2014 sehingga baru tumbu dan tentunya belum berbuah dan sebagian besar
Ada juga Kopi yang baru belajar berbuah dan kopi tersebut baru berumur sekitar tiga tahun dan dua tahunan dan ini berjajar di Desa Jatiarjo, Desa Dayurejo, Kelurahan Ledug serta Kelurahan Pecalukan hampir semua Desa Ada, Contoh Gambar : terhampar di wilaya Tahura R. Suryo dan sebagian di LMDH di dua Desa dan dua Kelurahan di atas.


Gambar 4. Foto Tanaman kopi baru tanam 


\section{Penguatan Kapasitas Kelompok Tani Kopi}

Dari hasil pemetaan di atas, terdapat beragamnya hasil kopi di setiap wilayah. Agar dalam proses pengembangan kopi ini lebih maksimal, maka dilakukan penguatan kapasitas bagi kelompok tani kopi.

Adapun bentuk penguatan yang sudah dilakukan dalam program KEHATi ini adalah: pertama, melalui pertemuan kelompok tani kopi secara berkala dengan berbagai stakeholders. Diantaranya adalah tim CSR PT. TIV., Yayasan Satu Daun, kelompok kopi puspa tani makmur. Setiap pertemuan kelompok ini selalu dilakukan pembacaan problem, perencanaan dan evaluasi hasil dari program yang sudah ditetapkan.

Kedua, penataan administrasi organisasi kelompok tani dengan membentuk AD/ART kelompok tani kopi, serta pembuatan Akte Notaris dan Badan Hukum Kelompok Puspa Tani Makmur di DEPHAM RI. Ketiga, pengembangan olahan produksi kopi, sampai dengan pengemasan yang sudah dilengkapi dengan PRT dari dinas kesehatan. Keempat, tata kelola administrasi keuangan dalam usaha budidaya dan olahan kopi.

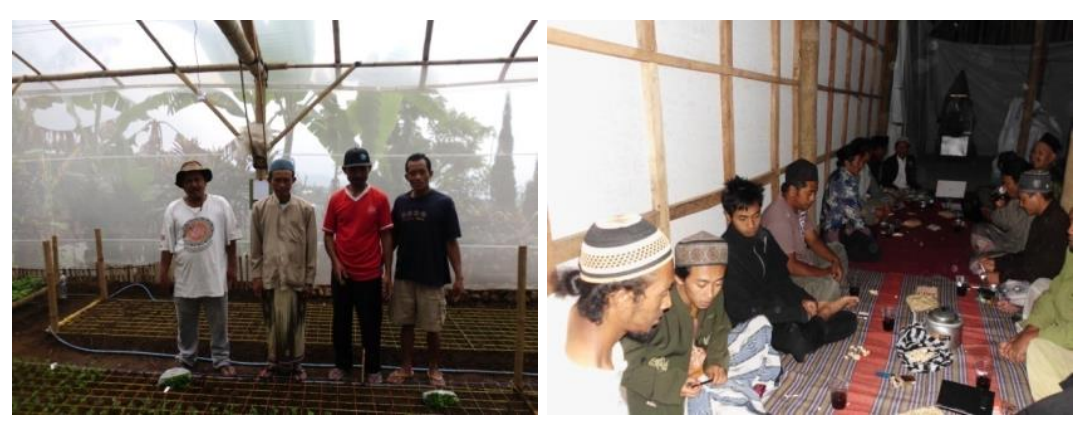

Gambar 5. Suasana penguatan kapasitas petani kopi

\section{Implementasi Penanaman Kopi berbasis Agroforestry}

Pengkayaan tanaman untuk kawasan hutan rakyat dengan model agroforestry dilakukan dengan melakukan penanaman tanaman kopi di Desa Jatiarjo, Dayurejo, Ledug dan Pecalukan. Adapun distribusi jumlah bibit tanaman kopi dan juga bibit pohon yang lain diurai dalam tabel berikut:

Tabel 2. Distribusi penanaman bibit kopi dan pohon lain berbasis agroforestry

\begin{tabular}{|c|c|c|c|}
\hline No & Desa & Jenis Bibit & Jumlah \\
\hline \multirow[t]{10}{*}{1} & \multicolumn{3}{|l|}{ Jatiarjo } \\
\hline & Dusun Tegal Kidul & Kopi & 1000 \\
\hline & \multirow[t]{7}{*}{ Dusun Cowek } & Kopi & 2500 \\
\hline & & Sengon & 1000 \\
\hline & & Nangka & 1000 \\
\hline & & Apukat & 700 \\
\hline & & Sirsat & 500 \\
\hline & & Srikoyo & 500 \\
\hline & & Aren & 100 \\
\hline & Dusun Tonggowa & Kopi & 5500 \\
\hline
\end{tabular}




\begin{tabular}{|c|c|c|c|}
\hline & & Sengon & 300 \\
\hline & \multicolumn{2}{|c|}{ Jumlah } & 13100 \\
\hline \multirow[t]{6}{*}{2} & \multicolumn{3}{|l|}{ Desa Dayurejo } \\
\hline & Dusun Dayu Kidul & Kopi & 1000 \\
\hline & Dusun Dayu Panji & Kopi & 1000 \\
\hline & Dusun Gutean & Sengon & 750 \\
\hline & Dusun Talunongko & Kopi & 1400 \\
\hline & \multicolumn{2}{|c|}{ Jumlah } & 3950 \\
\hline \multirow[t]{6}{*}{3} & \multicolumn{3}{|c|}{ Kelurahan Ledug } \\
\hline & \multirow[t]{3}{*}{ Geneng Barat } & Kopi & 700 \\
\hline & & Nangka & 200 \\
\hline & & Bendo & 100 \\
\hline & Paras & Kopi & 1500 \\
\hline & \multicolumn{2}{|c|}{ Jumlah } & 2500 \\
\hline 4 & Desa Sukolilo & Kopi & 500 \\
\hline
\end{tabular}

\section{Pengolahan Kopi}

Selain pendampingan tentang penanaman kopi berbasis agroforestry, PT. TIV Pandaan juga melakukan pendampingan untuk pengolahan hasil kopi. Adapun proses dalam pendampingan pengolahan kopi, yang sudah dilakukan pada 20 September 2015 di rumah Rumah Nuriyanto Ketua Kelompol Puspa tani Makmur Lingkungan Geneng Timur adalah sebagai berikut:

- Penggorengan Kopi

Kegiatan Pemecahan kulit Kopi agar cepat dalam pengeringan yang asalnya kering dengan penjemuran selama satu bulan apabila dilakukan dengan pemecahan kulit kopi bisa kering dengan hanya 8 [delapan] hari kopi sudah kering dan siap dilakukan penyelepan kelupas kulit kopi di selep padi kepada selep keliling.
Langkah selanjutnya adalah cara menggoreng kopi yang baik dan berkualitas bagus antara lain :

a. Pemanasan Mesin penggorengan dengan cara memakai Elpiji untuk menyalakan 2 [ dua ] Kompor yang ada di Mesin Penggorengan dengan suhu Mencapai 125' C" selama 13 Menit.

b. Penggorengan Pertama Kopi dengan kapasitas $10 \mathrm{Kg}$ dengan cara di masukkan kopi yang sudah di kupas dan keadaan kering kedalam penggorengan dalam keadaan suhu mencapai 125' C ,setelah di masukkan kopi suhu turun menjadi 100 ' $\mathrm{C}$ dan terus merangkak naik suhu panas penggorengan mencapai 137' $\mathrm{C}$ dengan lama penggorengan 35 Menit penggorengan Kedua dimasukkan Kopi kedalam penggorengan suhu dalam

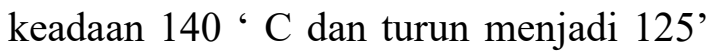
C dan terus merangka naik suhu panas 
mencapai $140^{\prime} \mathrm{C}$ dengan lama keadaan $145^{\prime} \mathrm{C}$ Turun Menjadi 140' C penggorengan selama 32 Menit

Dan Penggorengan Ke Tiga dimasukkan Kopi kedalam penggorengan suhu dalam merangka naik suhu panas mencapai $145^{\prime} \mathrm{C}$ dengan lama penggorengan selama 31 Menit


Gambar 6. Menggoreng kopi dengan mesin dan Blower Pendingin Korengan Kopi

- Pendinginan Kopi

Setelah kopi dalam penggorengan di rasa sudah matang maka kopi yang sudah matang di masukkan kedalam tempat Blower pendingin dengan cara di aduk agar cepat dingin agar kopi yang sudah matang tidak menjadi hangus/gosong. Selama 6-8 Menit

- Menjadi Bupuk Kopi

Kegiatan selanjutnya adalah memasukkan bubuk kopi yang sudah dingin ke dalam kapasitas penggorengan $60 \mathrm{Kg}$. pinggilingan bubuk kopi dengan cara dua kali penggilingan :

Pengilingan bubuk kopi Kasar Dengan Kapasitas Kopi sebesar $10 \quad \mathrm{Kg}$ pengilingan dilakukan selama 4 s/d 5 menit selesai

Penggilingan Bubuk Kopi Halus siap saji Dengan Kapasitas Kopi sebesar $10 \mathrm{Kg}$ pengilingan dilakukan selama 12 s/d 14 menit. Pelatihan selesai Jam, 13,45 Wib dengan

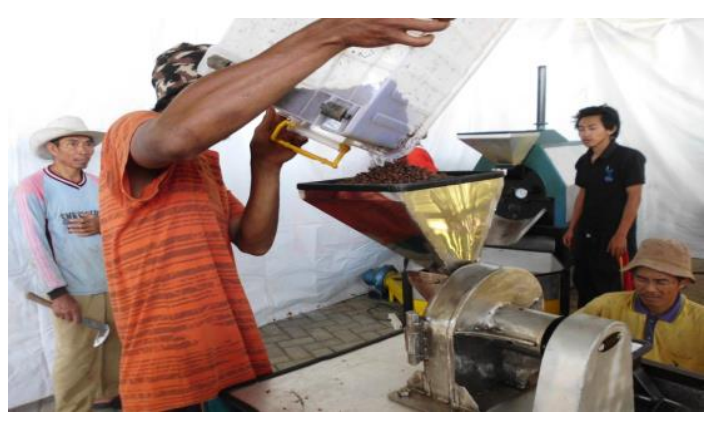

Gambar 7. Penggilingan Kopi Kolompok Kopi Puspa Tani Makmur

- Praktek Cara Pengemasan Produksi Kopi

Para peserta juga dilakukan pembekalan untuk melakukan pengisian bubuk kopi kedalam bungkus kemasan yang sudah di sediakan dengan bobot timbangan seberat 1[ satu ] On dan 2 [ dua ] on lalu dilakukan penyoletan dengan mesin dengan suhu Panas 178 C' S/d 180 C' 
Agar bungkus Kopi menjadi lengket dan Kopi bubuk Murni yang sudah di kemas siap di Jual dengan harga Rp 6000 untuk 1 [ satu ] On dan Rp 11000 untuk berat 2 [ dua ] On bagi yang kopi bubuk Murni biasa, dan bagi yang Kopi Murni Sepesial Rp 15000 dengan berat 2 [ dua ] On

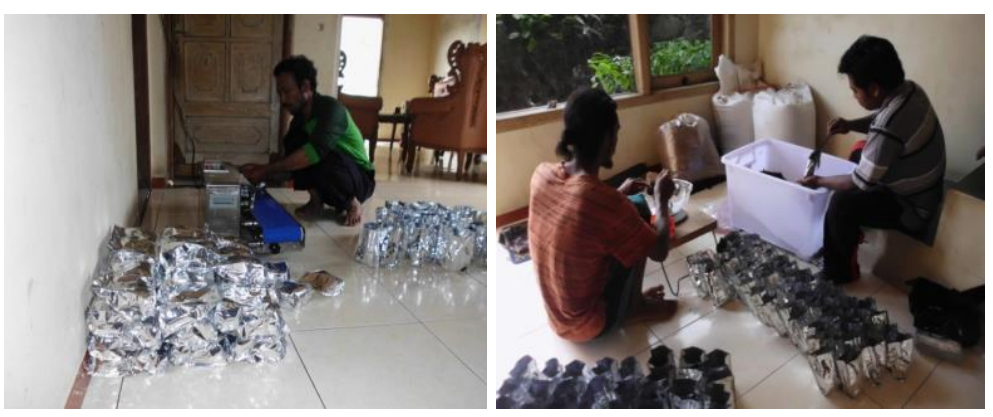

Gambar 8. Penyoletan/Pengemasan Bungkus Kopi serta Pengisian dan Penimbangan

\section{Kesimpulan}

CSR PT. TIV melalui program KEHATi telah melakukan pendampingan bagi Kelompok Kopi Puspa Tani Makmur di Kawasan Gunung Arjuna Prigren Pasuruan. Pendampingan ini dilakukan dengan penanaman pohon kopi berbasis agroforestry, sehingga konservasi hayati di Gunung Arjuna tetap terjaga dengan baik. Selain itu, para petani kopi juga dapat meningkatkan perekonomian mereka dengan mengelola kopi dengan baik, dimulai dari pengeringan, penggorengan menjadi bubuk kopi, sampai dengan pengemasan bubuk kopi.

\section{REFERENSI}

Atangana, A.et al.,2014. Tropical agroforestry, Netherlands:Springer Netherlands

Bruno Verbist, Andree Ekadinata Putra \& Suseno Budidarsono, 2004. PENYEBAB ALIH GUNA
LAHAN DAN AKIBATNYA TERHADAP FUNGSI DAERAH ALIRAN SUNGAI (DAS) PADA LANSEKAP AGROFORESTRI BERBASIS KOPI DI SUMATERA. AGRIVITA, 26(1), pp.29-38.

Buttoud, G., Place, F. \& Gauthier, M., 2013. Advancing Agroforestry on the Policy Agenda,

Educators, F. et al., 2000. Multipurpose Trees for Agroforestry in the Pacific Islands, Available at: http://www.agroforestry.net.

Jose, S., 2009. Agroforestry for ecosystem services and environmental benefits: An overview. Agroforestry Systems, 76(1), pp.1-10.

Jose, S. \& Bardhan, S., 2012. Agroforestry for biomass production and carbon sequestration: an overview. Agroforestry Systems, 86(2), pp.105-111. Available at: <Go to ISI $>$ ://WOS:000309670200001.

Margules, C.R. \& Pressey, R.L., 2000. Systematic conservation planning. Nature, 405(6783), pp.243-53. 
Van Noordwijk, M., 2008. AGROFORESTRI SEBAGAI SOLUSI MITIGASI DAN ADAPTASI PEMANASAN GLOBAL: Pengelolaan sumber daya alam yang berkelanjutan dan fleksibel terhadap berbagai perubahan. Bunga Rampai: Pendidikan agroforestri sebagai strategi menghadapi perubahan iklim global, (March), pp.13-41.

Pandey, D.N., 2007. Multifunctional agroforestry systems in India. Current Science, 92(4), pp.455463.

Senoaji, G., 2004. Pemanfaatan Hutan dan Lingkungan oleh Masyarakat Baduy di Banten Selatan. Manusia dan Lingkungan, XI(3), pp.143-149.

Suhartini, 2009. Peran Konservasi Keanekaragaman Hayati Dalam Menunjang Pembangunan Yang Berkelanjutan. Prosiding Seminar Nasional Penelitian, Pendidikan dan Penerapan MIPA, pp.199205.

Tim Penyusun, 2015. Dokumen Ringkasan Kinerja Pengelolaan Lingkungan (DRKPL-PROPER) 2015, Pasuruan.

Tim Penyusun, 2014. Laporan Akhir Tahun 2014: Hutan Asuh Tirta Investama Pandaan, Pasuruan.

Tim Penyusun CBR UIN Sunan Ampel Surabaya, 2015. Community Based Research: Sebuah Pengantar, Surabaya: SILE/LLD. 